\title{
Article \\ Multiple Primary Malignancies in Patients with Gynecologic Cancer
}

\author{
Eun-Jung Yang ${ }^{1}{ }^{(D}$, Ji-Hyeon Lee ${ }^{1}$, A-Jin Lee ${ }^{1}{ }^{\circledR}$, Nae-Ry Kim ${ }^{1}$, Yong-Taek Ouh ${ }^{2}$, Mi-Kyung Kim ${ }^{3}{ }^{(D}$, \\ Seung-Hyuk Shim ${ }^{1}$, Sun-Joo Lee ${ }^{1}$, Tae-Jin $\mathrm{Kim}^{1}{ }^{1}$ and Kyeong-A So ${ }^{1, *}$ \\ 1 Department of Obstetrics and Gynecology, KonKuk University Hospital, Seoul 05030, Korea; \\ manim486@hanmail.net (E.-J.Y.); 20190168@kuh.ac.kr (J.-H.L.); 20170050@kuh.ac.kr (A.-J.L.); \\ 20190125@kuh.ac.kr (N.-R.K.); 20130131@kuh.ac.kr (S.-H.S.); 1sj1121@kuh.ac.kr (S.-J.L.); \\ 20190002@kuh.ac.kr (T.-J.K.) \\ 2 Department of Obstetrics and Gynecology, Grauate School of Medicine, Kangwon National University, \\ Chuncheon 24289, Korea; oytijang@gmail.com \\ 3 Department of Obstetrics and Gynecology, Ewha Womans University Mokdong Hospital, Seoul 07804, Korea; \\ asterik79@gmail.com \\ * Correspondence: joyfulplace@hanmail.net; Tel.: +82-2-2030-7524
}

Citation: Yang, E.-J.; Lee, J.-H.; Lee, A.-J.; Kim, N.-R.; Ouh, Y.-T.; Kim, M.-K.; Shim, S.-H.; Lee, S.-J.; Kim, T.-J.; So, K.-A. Multiple Primary Malignancies in Patients with Gynecologic Cancer. J. Clin. Med. 2022, 11, 115. https://doi.org/ 10.3390/jcm11010115

Academic Editor: Yasuhiro Miki

Received: 3 December 2021

Accepted: 23 December 2021

Published: 26 December 2021

Publisher's Note: MDPI stays neutral with regard to jurisdictional claims in published maps and institutional affiliations.

Copyright: (C) 2021 by the authors. Licensee MDPI, Basel, Switzerland. This article is an open access article distributed under the terms and conditions of the Creative Commons Attribution (CC BY) license (https:// creativecommons.org/licenses/by/ $4.0 /)$.

\begin{abstract}
Objective: To investigate the prevalence and oncologic outcomes of patients with multiple primary malignant tumors (MPMT) with gynecologic cancer. Methods: This retrospective study included 1929 patients diagnosed with gynecologic cancer at a tertiary medical center between August 2005 and April 2021. The clinical data included cancer location, age at primary malignancy diagnosis, interval between primary and secondary cancer, stage of cancer, family history of cancer, genetic testing, dates of last follow-up, recurrence, and death. Results: The prevalence of MPMT with gynecologic cancer in patients was $8.6 \%$ and the mean diagnostic period between primary and secondary cancer was 60 months. Furthermore, 20 of the 165 patients with MPMT had multiple primary gynecologic cancers (MPGC), whereas 145 had gynecologic cancer coexisting with nongynecologic cancer (GNC). Endometrial-ovarian cancer $(60 \%)$ was the most common coexisting cancer in the MPGC group, whereas the most common non-gynecologic cancer in the GNC group was breast cancer (34.5\%). There were 48 patients with synchronous cancer and 117 patients with metachronous cancer. The incidence of synchronous cancer was higher in the MPGC group than in the GNC group $(p=0.037)$. Significantly more patients had early-stage ovarian cancer in the MPGC group than in the GNC group $(p=0.031)$. The overall recurrence and mortality rates were $15.8 \%$ and $8.5 \%$, respectively, in patients with MPMT. Conclusion: Synchronous cancer incidence was significantly higher in the MPGC than in the GNC group. Early-stage ovarian cancer was more highly diagnosed in patients with MPGC than in those with GNC. A systematic examination after primary cancer diagnosis could facilitate the early diagnosis of secondary primary malignancy, thereby improving patient prognosis.
\end{abstract}

Keywords: multiple primary malignant tumors; gynecologic cancers; synchronous malignancies; metachronous malignancies

\section{Introduction}

Gynecologic cancers consist of cancers that originate in the female reproductive system, the most common of which is uterine cancer, and these cancers often have multiple primary malignant tumors (MPMT). MPMT was first described in 1932 by Warren and Gates [1] who proposed the following definition as one or more tumors (1) all diagnosed as cancer, (2) all with different pathological origins, (3) and due to metastasis or recurrence are excluded [1]. Previous studies reported various MPMT prevalence rates as $0.4-21.0 \%$ [2-5], and the proportion of MPMT associated with gynecologic cancers was reported to be 1.9-4.3\% [6,7].

MPMT with gynecologic cancer can be divided into those with multiple primary gynecologic cancer (MPGC) and gynecologic cancer with non-gynecologic cancer (GNC) according to the type of comorbid cancer. GNC in patients is associated with breast [8-11], 
colorectal [9-13], bladder [9,11,13], kidney [11], and lung [12] cancers. In patients with MPGC, a combination of endometrial-ovarian cancer was the most common [14,15]. MPMT is further divided into synchronous or metachronous malignancy according to the time interval between the dates of diagnosis of one or more primary tumors [2]. A synchronous malignancy is defined as one where the diagnosis of the subsequent malignant tumor is made concurrently or within 6 months from the diagnosis date of the first primary malignancy. A metachronous malignancy refers to a diagnosis of a subsequent malignant tumor made $>6$ months after the first primary malignancy diagnosis [16-18]. Furthermore, $34-38 \%$ and $62-66 \%$ of MPMT have been reported to be synchronous and metachronous malignancies, respectively [2].

Treatment of MPMT requires the cautious and meticulous selection of appropriate approaches and treatment strategies. Treatment of the first primary malignancy should be planned to ensure that subsequent malignancies are not adversely affected by increased toxicity or pharmacological interactions [19]. Early diagnosis of subsequent malignancies is important because delayed diagnosis worsens the patient's prognosis. Currently, few studies have focused on MPMT in gynecologic cancer and, therefore, this study was conducted to investigate the clinical features and oncologic outcomes of MPMT in patients with gynecologic cancer.

\section{Materials and Methods}

In this study, which was approved by our institutional review board (IRB No. KUMC 2021-06-041), we retrospectively reviewed the medical records of 1929 patients with gynecologic cancers who presented at tertiary institution medical center between August 2005 and April 2021. All patient information and clinical data were archived in a central database at our institution. All patients diagnosed with MPMT with gynecologic cancer since the opening of our institute in August 2005 were enrolled in the study, except for those excluded based on the diagnostic criteria of Warren and Gates [1].

Gynecologic cancers considered in this study were cervical, ovarian, endometrial, and vulvovaginal cancers. Patients who met the study inclusion criteria were divided into the following two groups, according to the origin of the accompanying malignancy and the diagnosis period, which were comparatively analyzed. (1) Those diagnosed with one or more gynecologic cancers of different origins (MPGC group) or with gynecologic cancer coexisting with non-gynecologic cancer (GNC group) and (2) synchronous or metachronous cases based on a 6 month period between diagnosis dates.

The clinical data analyzed were collected by reviewing medical charts and consisted of cancer location, age at primary malignancy diagnosis, interval between primary and secondary cancer, stage of cancer, family history of cancer, genetic testing, and dates of last follow-up, recurrence, and death. Clinical analysis of the data in the study was conducted by classifying MPGC and GNC according to the accompanying primary cancer.

In addition, the tumors were further classified into synchronous and metachronous malignancies according to the diagnosis interval of primary cancer. The diagnosis date was determined when the histopathological diagnosis was confirmed. Progression-free survival (PFS) was defined as the duration from the date of diagnosis to the date of relapse or censoring, whereas overall survival (OS) was defined as the duration from the date of diagnosis to the date of death, last follow-up, or censoring.

All analyzes were performed using the statistical package for the social sciences (SPSS) software program version 22.0 (IBM SPSS Statistics, Chicago, IL, USA). Frequency distributions were analyzed using the chi-squared and Fisher's exact tests. Qualitative data are shown as frequencies and percentages, whereas quantitative data are presented as means \pm standard deviation (SD) or median and range. The Kaplan-Meier survival analysis was used to determine the PFS and OS. The results were compared using the log-rank test and a $p$-value $\leq 0.05$ was considered statistically significant. 


\section{Results}

\subsection{Site Distribution of Multiple Primary Malignant Tumors}

During the study period, 1929 patients with gynecologic cancer were enrolled, including 165 (8.6\%) who were diagnosed to have MPMT. In addition, 153 (92.7\%) and 12 (7.3\%) of the patients with MPMT had double and triple primary malignancies, respectively. The median follow-up period was 101.5 (range, 2-473) months. Furthermore, the mean age at diagnosis of the first and second primary cancer was 51.6 and 56.0 years, respectively. The most common site of the first primary cancer was the cervix $(21 \%)$, followed by the breast $(19 \%)$, ovaries $(17 \%)$, uterus $(16 \%)$, thyroid $(11 \%)$, colon/rectum $(11 \%)$, and others $(5 \%)$, identified in that order (Figure 1A). Other sites of the first primary cancer were the tonsils, skin, thighs, oral cavity, pancreas, kidneys, lungs, liver, bladder, hematologic, vagina, and stomach. The most common second primary cancer sites are listed in descending order of magnitude: uterus, ovary, cervix, thyroid, breast, colon/rectum, and others. (Figure 1B). The frequencies of the subsequent cancers according to primary cancer type are shown in Figure 2. Thyroid cancer was the most common second primary cancer in cervical cancer. Breast cancer occurred with the highest frequency as a subsequent cancer to ovarian cancer, whereas with endometrial cancer, breast and colorectal cancers had a high frequency as second primary cancers. Endometrial cancer was the most common second primary cancer following breast cancer.

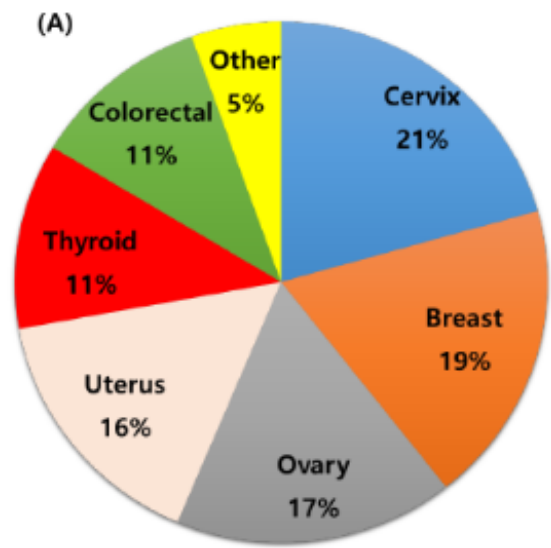

Other : tonsil, skin, thigh, oral cavity, pancreas, kidney, lung, liver, bladder, hematology, vagina, stomach

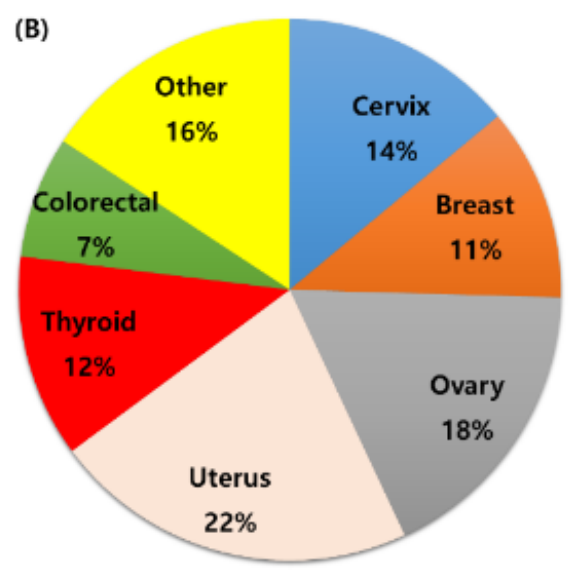

Other : tonsil, skin, thigh, oral cavity, pancreas, kidney, lung, liver, bladder, hematology, vagina, stomach

Figure 1. Site distribution of primary cancer. (A) First and (B) second primary cancers. 


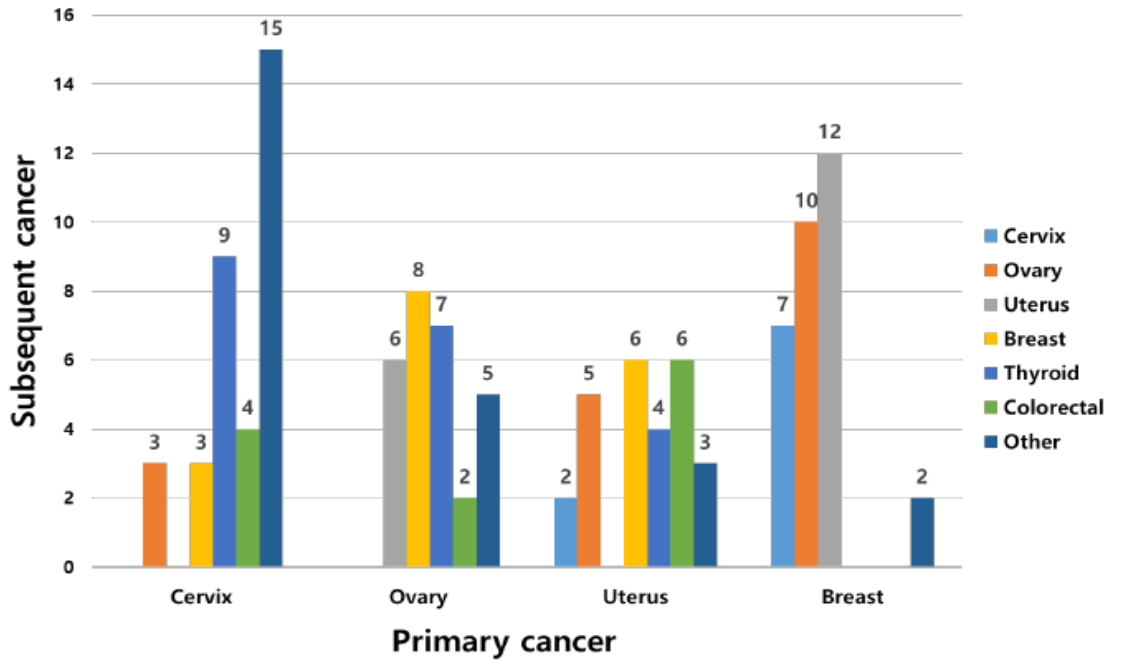

Other: tonsil, skin, thigh, oral cavity, pancreas, kidney, lung, liver, bladder, hematology, vagina, stomach

Figure 2. Frequency of subsequent cancer according to primary cancer type.

3.2. Gynecologic Cancer Coexisting with Non-Gynecologic Cancer (GNC) and Multiple Primary Gynecologic Cancers (MPGC)

Of the 165 patients, 145 (87.9\%) and 20 (12.1\%) were diagnosed with GNC and MPGC, respectively. Furthermore, in the MPGC group, ovarian-endometrial cancer was the most common (12 patients), followed by ovarian-cervical cancer (4 patients), cervicalendometrial cancer ( 2 patients), and cervical-vaginal cancer ( 2 patients). The most common non-gynecologic cancer associated with gynecologic cancer in the GNC group was breast cancer $(50 / 145,34.5 \%)$. There were $33(22.7 \%)$ patients diagnosed with breast cancer as the first cancer before gynecologic cancer, while there were $17(11.7 \%)$ patients diagnosed with breast cancer as the subsequent cancer to gynecologic cancer in the GNC group. There were 13 patients with breast-endometrial cancer, 10 patients with breast-ovarian cancer, and 10 patients with breast-cervical cancer. Furthermore, 7 of the 13 patients with breast-endometrial cancer received anti-estrogen therapy after breast cancer surgery.

The comparison of the clinical characteristics between the GNC and MPGC groups shown in Table 1. There were no significant differences in the age at the time of first cancer diagnosis and the diagnostic period between first and second cancers between both groups. However, $50 \%$ of patients in the MPGC group were diagnosed with synchronous malignancies, which was a significantly higher percentage than the $26.2 \%$ of patients in the GNC group ( $p=0.037)$. The synchronous malignancies in the MPGC group consisted of 8 and 2 cases of ovarian-endometrial and endometrial-cervical cancers, respectively. When analyzed according to the primary gynecology cancer site, ovarian cancer showed a higher rate of early-stage disease in patients with MPGC than in those with GNC (87.5\% vs. 52.4\%, $p=0.031)$. However, there was no significant difference in early-stage disease between the GNC group and the MPGC group in endometrial cancer and cervical cancer. The overall recurrence rate was $15.8 \%(26 / 165)$ in patients with MPMT. During the study period, $21(14.5 \%)$ and $5(25.0 \%)$ patients in the GNC and MPGC groups relapsed, respectively. According to the primary cancers, the recurrence rate were $76.9 \%$ and $23.1 \%$ in gynecologic cancer and non-gynecologic cancer, respectively. The mortality rate was $8.5 \%(14 / 165)$ with 13 patients from the GNC group and 1 patient from the MPGC group. The distribution of the direct cause of death was gynecologic (64.3\%) and non-gynecologic cancer (35.7\%), with ovarian cancer as the most common cause of death. The 5-year PFS and 5-year OS were not significantly different between the GNC and MPGC groups ( $p=0.166$ and $p=0.865$, respectively, Figure 3A,B). 
Table 1. Comparison of patient characteristics between non-gynecologic cancer (GNC) and multiple primary gynecologic cancers (MPGC).

\begin{tabular}{cccc}
\hline Variables & GNC $(\mathbf{N}=\mathbf{1 4 5})$ & MPGC $\mathbf{~ N ~ = ~ 2 0 ) ~}$ & $p$-Value \\
\hline Age at diagnosis of first cancer, yr & $52.3 \pm 12.4$ & $45.7 \pm 9.3$ & 0.377 \\
Interval between 1st and 2nd cancer, & $41.5(0-420)$ & $5.5(0-241)$ & 0.992 \\
mo & $38(26.2 \%)$ & $10(50.0 \%)$ & 0.037 \\
Synchronous cancer, $n(\%)$ & & 0.031 \\
Stage of OC, $n(\%)$ & & $14(87.5)$ & \\
I-II & $22(52.4)$ & $1(6.3)$ & \\
III-IV & $16(38.1)$ & $1(6.3)$ & \\
unknown & $4(9.5)$ & $12(85.7)$ & \\
Stage of EC, $n(\%)$ & $35(72.9)$ & $2(14.3)$ & \\
I-II & $12(25.0)$ & & \\
III-IV & $1(2.1)$ & & \\
unknown & $5(62.5)$ & \\
I-II & Stage of CC, $n(\%)$ & 0.449 \\
III-IV & $69(72.2)$ & $3(37.5)$ & \\
unknown & $9(11.1)$ & $1(5.0)$ & \\
Died disease, $n(\%)$ & $13(9.0)$ & $5(25.0)$ & 0.321 \\
Recurrence of disease, $n(\%)$ & $21(14.5)$ & & \\
\hline
\end{tabular}

Abbreviations: GNC, gynecologic cancer coexisting with non-gynecologic cancer; MPGC, multiple primary gynecologic cancer; OC, ovarian cancer; EC, endometrial cancer; $C$, cervical cancer.
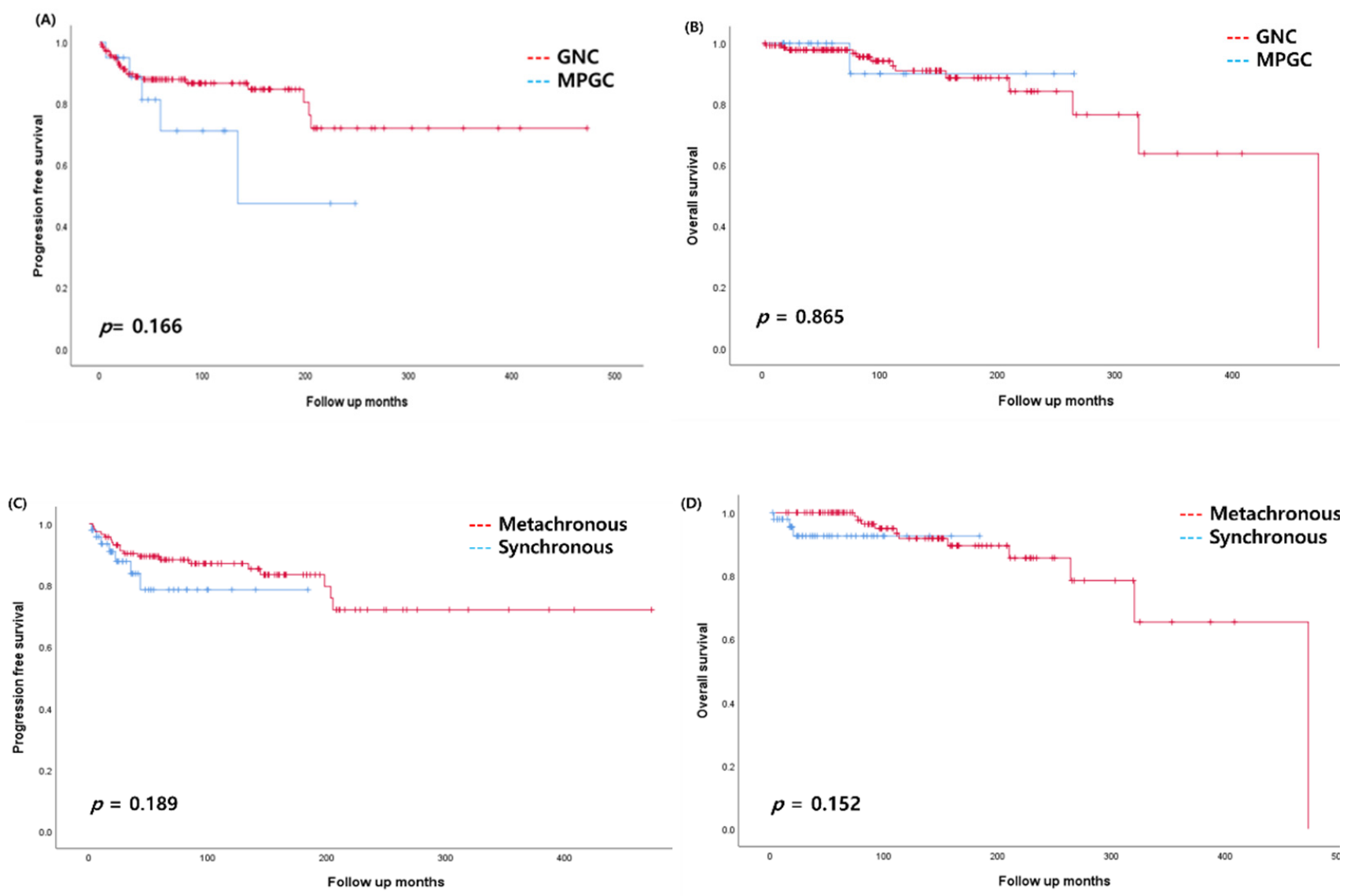

Figure 3. Progression-free survival (PFS) and overall survival (OS) of patients with multiple primary malignant tumors (MPMT) with gynecologic cancer. Comparisons of (A) PFS and (B) OS between patients with multiple primary gynecologic cancer (MPGC) and gynecologic cancer coexisting with non-gynecologic cancer (GNC). Comparison of (C) PFS and (D) OS between patients with synchronous and metachronous malignancies. 


\subsection{Synchronous and Metachronous Malignancies}

Forty-eight and 117 patients had synchronous and metachronous malignancies, respectively (Table 2). The mean diagnostic interval between the first and second primary cancers in the metachronous malignancies group was 60 months. The most synchronous malignancies were ovarian-endometrial cancer in 8 patients, followed by ovarian-breast cancer in 7 patients, endometrial-breast cancer in 5 patients, and ovarian-thyroid cancer in 5 patients. The mean age at diagnosis for the first primary cancer was 55.4 years and 50.2 years in the synchronous and metachronous malignancies groups, respectively. The metachronous malignancies group showed a tendency to be diagnosed with cancer at a younger age than the synchronous malignancies group $(p=0.050)$. The age at diagnosis was not different according to the types of gynecologic cancer. However, more patients with cervical cancer were diagnosed at the early stage in the metachronous malignancies group than in the synchronous malignancies group $(72.3 \%$ vs. $63.6 \%, p=0.015)$. There were no significant differences between the stage at diagnosis for ovarian and endometrial cancers between the two groups. There was no difference in the 5-year PFS and OS between the synchronous and metachronous malignancies groups $(p=0.189$ and $p=0.152$, respectively, Figure $3 \mathrm{C}, \mathrm{D})$.

Table 2. Patient characteristics compared between synchronous malignancies and metachronous malignancies.

\begin{tabular}{|c|c|c|c|}
\hline Variables & $\begin{array}{c}\text { Synchronous } \\
\text { Malignancies } \\
(\mathrm{N}=48)\end{array}$ & $\begin{array}{l}\text { Metachronous } \\
\text { Malignancies } \\
\quad(\mathbf{N}=117)\end{array}$ & $p$-Value \\
\hline $\begin{array}{l}\text { Age at diagnosis of } \\
\text { first cancer, yr }\end{array}$ & $55.4 \pm 12.9$ & $50.2 \pm 11.7$ & 0.050 \\
\hline \multicolumn{2}{|c|}{ Stage of OC, $n(\%)$} & & 0.817 \\
\hline I-II & $11(64.7)$ & $17(47.2)$ & \\
\hline III-IV & $5(29.4)$ & $12(33.3)$ & \\
\hline unknown & $1(5.9)$ & $3(8.3)$ & \\
\hline \multicolumn{2}{|c|}{ Stage of EC, $n(\%)$} & & 0.392 \\
\hline I-II & $12(63.2)$ & $28(73.7)$ & \\
\hline III-IV & $6(31.6)$ & $10(26.3)$ & \\
\hline unknown & $1(5.3)$ & 0 & \\
\hline \multicolumn{2}{|c|}{ Stage of CC, $n(\%)$} & & 0.015 \\
\hline I-II & $7(63.6)$ & $34(72.3)$ & \\
\hline III-IV & $4(36.4)$ & $3(6.4)$ & \\
\hline unknown & 0 & $10(21.3)$ & \\
\hline
\end{tabular}

Abbreviations: OC, ovarian cancer; EC, endometrial cancer; $\mathrm{CC}$, cervical cancer.

\subsection{Multiple Primary Malignancies in Gynecologic Patients with Genetic Testing}

Genetic testing has been conducted at our medical institution for hereditary nonpolyposis colorectal cancer (HNPCC) since 2007 and the breast cancer gene (BRCA) since 2017. Nineteen patients underwent the genetic test during the study period and $10(52.6 \%)$ showed positive results as follows: 7 HNPCC, 2 BRCA1, and 1 BRCA2 mutation, respectively. All 10 patients with mutations confirmed by genetic testing were in the GNC group and the results are shown in Table 3. 
Table 3. Multiple primary malignancies in patients with gynecologic cancer with positive genetic test results $(n=10)$.

\begin{tabular}{|c|c|c|c|c|c|c|c|}
\hline $\begin{array}{l}\text { Genetic Test } \\
\text { Result }\end{array}$ & FHC & $\begin{array}{c}\text { First Caner, } \\
\text { Age at } \\
\text { Diagnosis }\end{array}$ & $\begin{array}{l}\text { Recurrence } \\
\text { PFS, mo }\end{array}$ & $\begin{array}{l}\text { Status, Time to } \\
\text { Survival, mo }\end{array}$ & $\begin{array}{c}\text { Second } \\
\text { Cancer, Age } \\
\text { at Diagnosis, } \\
\text { mo }\end{array}$ & $\begin{array}{l}\text { Recurrence, } \\
\text { PFS, mo }\end{array}$ & $\begin{array}{c}\text { Status, Time to } \\
\text { Survival, mo }\end{array}$ \\
\hline HNPCC & No & $\begin{array}{l}\text { Endometrium } \\
37\end{array}$ & No & Remission 10 & $\begin{array}{c}\text { Colorectal } \\
37\end{array}$ & No & Remission 9 \\
\hline HNPCC & No & $\begin{array}{l}\text { Endometrium } \\
64\end{array}$ & No & Remission 82 & $\begin{array}{c}\text { Colorectal } \\
64\end{array}$ & No & Remission 81 \\
\hline HNPCC & Yes & Colorectal 35 & Yes 45 & Remission 52 & $\begin{array}{l}\text { Endometrium } \\
48\end{array}$ & Lost to FU & Lost to FU 0 \\
\hline HNPCC & Yes & Colorectal 31 & No & Lost to FU 164 & $\begin{array}{l}\text { Endometrium } \\
\qquad 44\end{array}$ & Lost to FU & Lost to FU 2 \\
\hline HNPCC & No & Colorectal 60 & No & Remission 43 & Cervix 61 & No & Remission 28 \\
\hline HNPCC & No & Cervix 50 & No & Remission 23 & $\begin{array}{c}\text { Colorectal } \\
50\end{array}$ & No & Remission 22 \\
\hline HNPCC & No & Colorectal 41 & Yes 60 & Remission 325 & Ovary 48 & No & Lost to FU 241 \\
\hline
\end{tabular}

\section{Discussion}

MPMT with gynecologic cancers was identified at a prevalence rate of $8.6 \%$ in this study, which is higher than that in previous studies $(1.9-4.3 \%)$ [6,7]. This observation suggests that the incidence of MPMT is increasing in relation to several factors, including increased life expectancy, effective screening, accurate diagnosis of malignancies, extensive systematic evaluation for first primary cancers, and long-term follow-up after cancer treatment [20]. Among patients with MPMT with gynecologic cancers, the number of those with GNC was approximately seven times greater than those with MPGC $(87.9 \%$ vs. $12.1 \%$, respectively) in this study. There were no significant differences in age at first cancer diagnosis, diagnostic interval between primary cancers, recurrence rate, and mortality rate between the GNC and MPGC groups. However, the MPGC group had a higher rate of synchronous malignancies than that of the GNC group (50.0\% vs. $26.2 \%$, respectively, $p=0.037$ ). In addition, ovarian cancer showed a tendency to be diagnosed at an early stage when it was accompanied by gynecologic cancer but not when accompanied by non-gynecologic cancer $(87.5 \%$ vs. $52.4 \%, p=0.031)$. Several reasons could explain the differences between the GNC and MPGC groups. First, second primary gynecologic cancers may have been fortuitously diagnosed during the surgical staging operation of primary gynecologic cancer. The surgical staging operation usually involves a hysterectomy and salpingo-oophorectomy, which can lead to the detection of a second symptomless primary gynecologic cancer at an early stage. Second, these results could also be explained by the incidental discovery of an asymptomatic second primary gynecologic cancer through hemodynamic testing, computed tomography (CT), and magnetic resonance imaging (MRI). These tests are routinely performed for preoperative tumor evaluation when a patient is diagnosed with primary cancer in our institute. The results of the data analysis of the patients in the MPGC group at our medical center confirmed that $80 \%$ were diagnosed with the second primary gynecologic cancer after surgery for primary gynecologic cancer. Furthermore, $20 \%$ of patients were diagnosed with preoperative tumor evaluation before primary gynecologic cancer surgery.

Breast cancer was the most common non-gynecologic cancer in the GNC group. Previous studies showed that breast cancer had a higher rate of occurrence as the first primary cancer before the diagnosis of gynecologic cancer than it did as a second diagnosed primary cancer following gynecologic cancer $[21,22]$. In this study, as a second primary gynecologic cancer associated with breast cancer, endometrial cancer occurred in 13 patients, including 7 (53.8\%) with a history of anti-estrogen therapy. Tamoxifen has an anti-estrogenic 
effect on breast tissue, but has an estrogenic effect on the uterus, and increases the risk of endometrial cancer by 2 to 7 times with long-term use [23]. In addition, high-grade or high-risk types of endometrial cancer are more developed in breast cancer patients after tamoxifen treatment [21]. Therefore, surveillance for other cancers is necessary for patients with breast cancer during anti-estrogen therapy.

Previous studies reported that the proportion of patients with MPGC was higher than that of patients with GNC, and the rate of diagnosis at the early stage of gynecologic cancer was high [20]. There was no difference in the 5-year OS, but the 5-year PFS was confirmed to be longer in the GNC group than it was in the MPGC group [20]. However, there was no difference between the 5-year PFS and OS in this study. The survival outcome results of the patients in this study were different from the results of previous studies according to the distribution of patients with MPMT with gynecologic cancer in our institution. Compared with the findings of previous studies, those of our study suggest that early diagnosis of cancer is an important factor in determining the prognosis of cancer in patients with MPMT.

The synchronous group in which the subsequent cancer was diagnosed within 6 months after the primary cancer was predicted to have a higher early diagnosis rate than that of the metachronous group. However, in patients with cervical cancer, the early diagnosis rate was higher in the metachronous group than it was in the synchronous group $(p=0.015)$. This was likely because the early detection of cervical cancer is increasing and the number of patients in the metachronous group was relatively higher than that in the synchronous group. The diagnostic interval between primary cancers of different origins of metachronous malignancy has been found to be 3-10 years $[21,24,25]$. The second cancer was diagnosed an average of 5 years after the diagnosis of primary gynecologic cancer in this study. The result shows that attention should also be focused on the long-term surveillance of second cancers in patients with gynecology cancer. Gynecologic cancers, in particular, cause difficulty for women of reproductive age to remain fertile [26]. Maintaining fertility in women of reproductive age can contribute greatly to a patient's quality of life $[27,28]$. In this study, $68(41.2 \%)$ patients with gynecological cancer were diagnosed with a first primary cancer before menopause. If a woman with reproductive potential is diagnosed with gynecological cancer at an early stage, measures to maintain fertility should be considered in accordance with the guidelines for preserving fertility [29,30].

Previous studies have shown that genetic mutations cause MPMT [31-33]. Approximately $5 \%$ and $10 \%$ of endometrial and ovarian cancer, respectively are caused by genetic predisposition [31,32]. Women with the BRCA1 mutation have a 39-46\% and $65-85 \%$ risk of developing ovarian and breast cancers, respectively [33]. The reported risk of ovarian and breast cancers in women with a BRCA2 mutation is $10-27 \%$ and $45-85 \%$, respectively [33]. Lynch syndrome, also known as HNPCC syndrome, accounts for most hereditary endometrial cancers. Lynch syndrome is most commonly associated with colorectal and endometrial cancer, with a lifetime risk of 40-60\% [33]. MPMT in gynecologic cancers may be caused by a genetic predisposition and genetic testing can predict the likelihood of subsequent cancers. In this study, the genetic testing rate was low because of its late introduction to our hospital. Genetic testing should be considered because it facilitates the prediction of the likelihood of MPMT, improves patient prognosis, and has preventive effects.

Although this study has limitations as a retrospective study conducted at a single medical institution, it also has the following several strengths. First, this study was conducted on all patients with MPMT associated with gynecologic cancers for $>10$ years in real clinical practice. Second, we identified the characteristics of each group by distinguishing the diagnosis time and origin of MPMT in patients with gynecologic cancer. Further large-scale prospective studies with long-term follow-up data are needed to evaluate the clinical implications of multiple primary malignancies.

In conclusion, systematic examination after diagnosis of primary gynecologic cancer would facilitate the diagnosis of second primary cancer. Because secondary malignancies are diagnosed an average of 5 years after the primary malignancies, attention should be paid to long-term surveillance of secondary malignancies in patients with gynecologic 
cancer. In addition, because there may be a risk of secondary malignancy following the treatment of primary cancer, it is important to monitor the occurrence of additional cancer in patients receiving cancer treatment. Although no significant difference in survival outcome were identified in this study, early diagnosis of MPMT is thought to improve the prognosis of patients and help to preserve the fertility of women of reproductive age. The results of this study may be useful in the early diagnosis of MPMT in patients with gynecologic cancer and may contribute to developing strategies to conduct surveillance of patients with gynecologic cancer to monitor the risk of a second malignancy.

Author Contributions: Conceptualization: K.-A.S.; data curation: J.-H.L.; formal analysis: E.-J.Y.; investigation: A.-J.L. and N.-R.K.; methodology: Y.-T.O. and M.-K.K.; project administration: K.-A.S.; resources: K.-A.S., S.-H.S., S.-J.L., and T.-J.K.; supervision: K.-A.S.; validation: K.-A.S.; visualization: E.-J.Y.; writing-original draft: K.-A.S. and E.-J.Y.. All authors have read and agreed to the published version of the manuscript.

Funding: The authors of this publication do not have any sources of research funding.

Institutional Review Board Statement: Written informed consent was obtained from all participants of the study. The study was conducted in accordance with the Declaration of Helsinki, and the protocol was approved by the Ethics Committee of Konkuk University hospital (approval number: KUMC 2021-06-041).

Informed Consent Statement: Not applicable.

Data Availability Statement: All the studies used in this study are published in the literature.

Conflicts of Interest: All the authors declare no conflict of interest.

\section{References}

1. Warren, S. Multiple primary malignant tumors. A survey of the literature and a statistical study. Am. J. Cancer 1932, 16, 1358-1414.

2. $\quad$ Babacan, N.A.; Aksoy, S.; Cetin, B.; Ozdemir, N.Y.; Benekli, M.; Uyeturk, U.; Ali Kaplan, M.; Kos, T.; Karaca, H.; Oksuzoglu, B.; et al. Multiple primary malignant neoplasms: Multi-center results from Turkey. J. BUON 2012, 17, 770-775. [PubMed]

3. Liu, F.S.; Qin, D.X.; Wang, Q.L. A clinico-pathological analysis of 172 patients with multiple primary malignant tumors (MPMT). Zhonghua Zhong Liu Za Zhi 1979, 1, 113-119. [PubMed]

4. Macdonald, E.J. Occurrence of multiple primary cancers in a population of 200. Acta Unio Int. Contra Cancrum 1960, 16, 1702-1710. [PubMed]

5. Frödin, J.E.; Ericsson, J.; Barlow, L. Multiple primary malignant tumors in a national cancer registry-Reliability of reporting. Acta Oncol. 1997, 3, 465-469. [CrossRef] [PubMed]

6. Takeda, T.; Sagae, S.; Koizumi, M.; Terasawa, K.; Ishioka, S.; Takashima, S.; Kudo, R. Multiple primary malignancies in patients with gynecologic cancer. Int. J. Gynecol. Cancer 1995, 5, 34-39. [CrossRef] [PubMed]

7. Liu, Z.; Liu, C.; Guo, W.; Li, S.; Bai, O. Clinical analysis of 152 cases of multiple primary malignant tumors in 15,398 patients with malignant tumors. PLoS ONE 2015, 10, e0125754. [CrossRef]

8. Ewertz, M.; Storm, H.H. Multiple primary cancers of the breast, endometrium and ovary. Eur. J. Cancer Clin. Oncol. 1989, 25, 1927-1932. [CrossRef]

9. Reimer, R.R.; Hoover, R.; Fraumeni, J.F.; Young, R.C. Second primary neoplasm following ovarian cancer. J. Natl. Cancer Inst. 1978, 61, 1195-1197. [CrossRef]

10. Shah, S.; Evans, D.G.; Blair, V.; Burnell, L.D.; Birch, J.M. Assessment of relative risk of second primary tumors after ovarian cancer and of the usefulness of double primary cases as a source of material for genetic studies with a cancer registry. Cancer 1993, 72 , 819-827. [CrossRef]

11. Brenner, H.; Siegle, S.; Stegmaier, C.; Ziegler, H. Second primary malignancies following gynecologic tumours in Saarland, Germany, 1968. J. Cancer Res. Clin. Oncol. 1993, 119, 179-183. [CrossRef]

12. Coleman, M.P.; Bell, C.M.; Fraser, P. Second primary malignancy after Hodgkin's disease, ovarian cancer and cancer of the testis: A population-based cohort study. Br. J. Cancer 1987, 56, 349-355. [CrossRef]

13. Kaldor, J.M.; Day, N.E.; Band, P.; Choi, N.W.; Clarke, E.A.; Coleman, M.P.; Hakama, M.; Koch, M.; Langmark, F.; Neal, F.E.; et al. Second malignancies following testicular cancer, ovarian cancer and Hodgkin's disease: An international collaborative study among cancer registries. Int. J. Cancer 1987, 39, 571-585. [CrossRef]

14. Tong, S.Y.; Lee, Y.S.; Park, J.S.; Bae, S.N.; Lee, J.M.; Namkoong, S.E. Clinical analysis of synchronous primary neoplasms of the female reproductive tract. Eur. J. Obstet. Gynecol. Reprod. Biol. 2008, 136, 78-82. [CrossRef] [PubMed]

15. Eser, S.; Gulhan, I.; Ozdemir, R.; Dicle, N.; Hanhan, M.; Baloglu, A.; Ozsaran, A.; Saygili, U. Synchronous primary cancers of the female reproductive tract in Turkish women. Asian Pac. J. Cancer Prev. 2011, 12, 857-859. [PubMed] 
16. Suzuki, T.; Takahashi, H.; Yao, K.; Inagi, K.; Nakayama, M.; Makoshi, T.; Nagai, H.; Okamoto, M. Multiple primary malignancies in the head and neck: A clinical review of 121 patients. Acta Otolaryngol. Suppl. 2002, 547, 88-92. [CrossRef]

17. Morris, L.G.; Sikora, A.G.; Patel, S.G.; Hayes, R.B.; Ganly, I. Second primary cancers after an index head and neck cancer: Subsite-specific trends in the era of human papillomavirus-associated oropharyngeal cancer. J. Clin. Oncol. 2011, 29, 739-746. [CrossRef] [PubMed]

18. Cheng, H.Y.; Chu, C.H.; Chang, W.H.; Hsu, T.C.; Lin, S.C.; Liu, C.C.; Yang, A.M.; Shih, S.C. Clinical analysis of multiple primary malignancies in the digestive system: A hospital based study. World J. Gastroenterol. 2005, 11, 4215-4219. [CrossRef]

19. Vogt, A.; Schmid, S.; Heinimann, K.; Frick, H.; Herrmann, C.; Cerny, T.; Omlin, A. Multiple primary tumours: Challenges and approaches, a review. ESMO Open 2017, 2, e000172. [CrossRef] [PubMed]

20. Jareemit, N.; Ruengkhachorn, I.; Therasakvichaya, S.; Warnnissorn, M.; Jaishuen, A.; Likhitsup, A. Multiple Primary Malignancies in Gynecologic Cancer Patients in Thai Tertiary Care Center: A 10-Year Retrospective Study. Siriraj Med. J. 2018, 70, 310-319. [CrossRef]

21. Martin-Dunlap, T.M.; Wachtel, M.S.; Margenthaler, J.A. Outcomes for patients who are diagnosed with breast and endometrial cancer. Oncol. Lett. 2013, 6, 1103-1107. [CrossRef]

22. Liou, W.S.; Hamilton, C.A.; Cheung, M.K.; Osann, K.; Longacre, T.A.; Teng, N.N.; Husain, A.; Dirbas, F.M.; Chan, J.K. Outcomes of women with metachronous breast and ovarian carcinomas. Gynecol. Oncol. 2006, 103, 190-194. [CrossRef]

23. Bergman, L.; Beelen, M.L.; Gallee, M.P.; Hollema, H.; Benraadt, J.; van Leeuwen, F.E. Risk and prognosis of endometrial cancer after tamoxifen for breast cancer; Comprehensive Cancer Centres' ALERT Group. Assessment of Liver and Endometrial cancer Risk following Tamoxifen. Lancet 2000, 356, 881-887. [CrossRef]

24. Tangjitgamol, S.; Khunnarong, J.; Srijaipracharoen, S. Synchronous and metachronous malignancy in endometrial cancer patients treated in a tertiary care center of Thailand. J. Gynecol. Oncol. 2015, 26, 293-302. [CrossRef]

25. Grzankowski, K.S.; Szender, J.B.; Spring-Robinson, C.L.; Lele, S.B.; Odunsi, K.O.; Frederick, P.J. Evaluation of Metachronous Breast and Endometrial Cancers: Preroutine and Postroutine Adjuvant Tamoxifen Use. Int. J. Gynecol. Cancer 2016, 26, 1440-1447. [CrossRef]

26. Vitale, S.G.; La Rosa, V.L.; Rapisarda, A.M.C.; Laganà, A.S. The Importance of Fertility Preservation Counseling in Patients with Gynecologic Cancer. J. Reprod. Infertil. 2017, 18, 261-263.

27. Vitale, S.G.; La Rosa, V.L.; Rapisarda, A.M.C.; Lagana, A.S. Psychology of infertility and assisted reproductive treatment: The Italian situation. J. Psychosom. Obst. Gyn. 2017, 38, 1-3. [CrossRef] [PubMed]

28. Angarita, A.M.; Johnson, C.A.; Fader, A.N.; Christianson, M.S. Fertility Preservation: A Key Survivorship Issue for Young Women with Cancer. Front. Oncol. 2016, 6. [CrossRef] [PubMed]

29. Oktay, K.; Harvey, B.E.; Partridge, A.H.; Quinn, G.P.; Reinecke, J.; Taylor, H.S.; Wallace, W.H.; Wang, E.T.; Loren, A.W. Fertility Preservation in Patients with Cancer: ASCO Clinical Practice Guideline Update. J. Clin. Oncol. 2018, 19, 1994-2001. [CrossRef]

30. Chiofalo, B.; Palmara, V.; Laganà, A.S.; Triolo, O.; Vitale, S.G.; Conway, F.; Santoro, G. Fertility Sparing Strategies in Patients Affected by Placental Site Trophoblastic Tumor. Curr. Treat. Options. Oncol. 2017, 18, 58. [CrossRef] [PubMed]

31. Gruber, S.B.; Thompson, W.D. A population-based study of endometrial cancer and familial risk in younger women. Cancer and hormone study group. Cancer Epidemiol. Biomark. Prev. 1996, 5, 411-417. [PubMed]

32. Meyer, L.A.; Broaddus, R.R.; Lu, K.H. Endometrial cancer and Lynch syndrome: Clinical and pathologic considerations. Cancer Control 2009, 16, 14-22. [CrossRef] [PubMed]

33. Lancaster, J.M.; Powell, C.B.; Chen, L.M.; Richardson, D.L. Society of Gynecologic Oncology statement on risk assessment for inherited gynecologic cancer predispositions. Gynecol. Oncol. 2015, 136, 3-7. [CrossRef] [PubMed] 